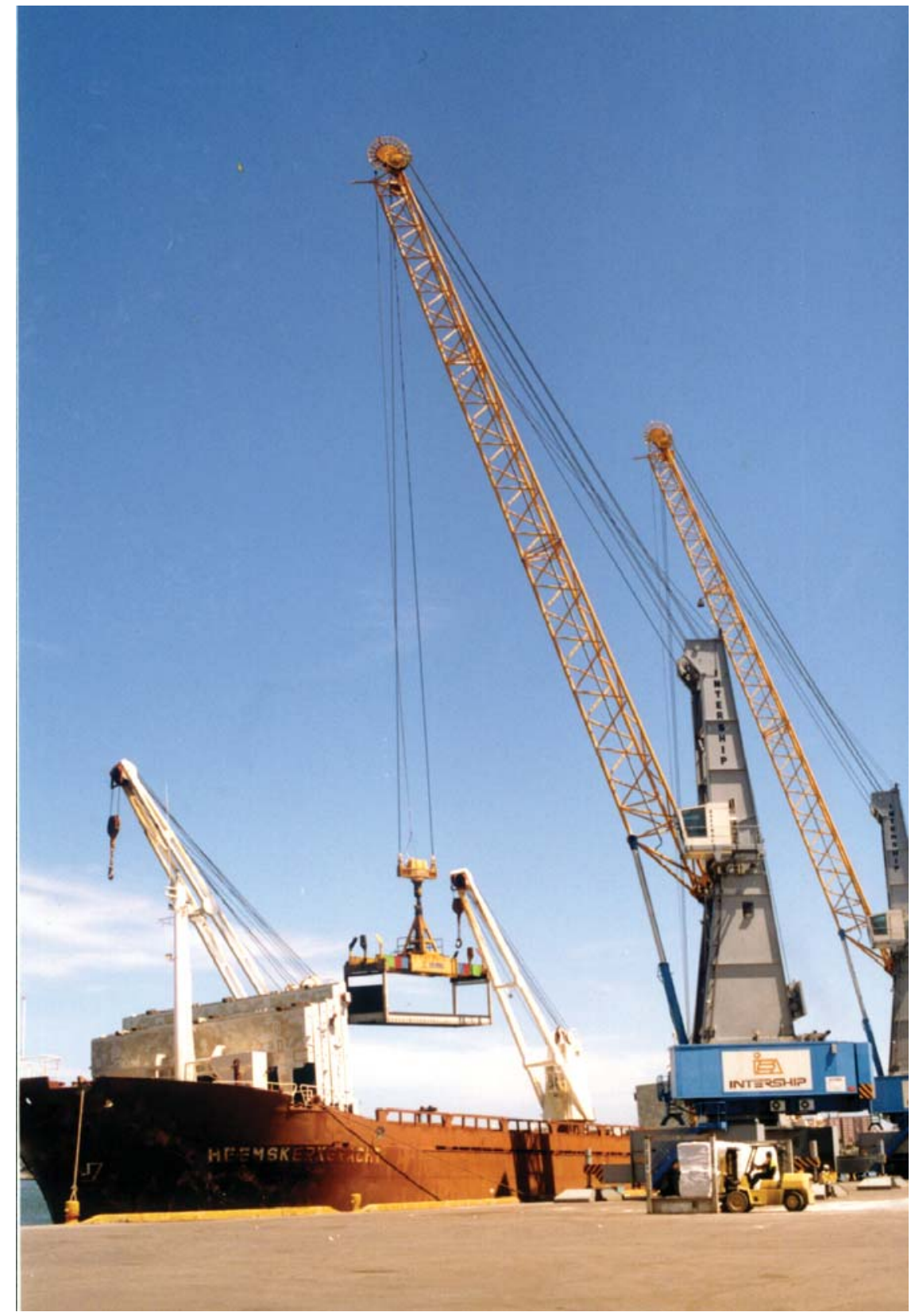




\title{
Resumen
}

La competitividad se constituye hoy día como el "nuevo" paradigma que permite triunfar en el mercado global. De ser así, es inevitable preguntarse, si acaso, en tiempos pasados no se requería ser competitivo para tener éxito en el comercio internacional. Reconociendo la discusión en torno al tema y su densidad teórico-conceptual, en el presente trabajo se estudia esta vieja noción. Su significado, en esencia, es el mismo de siempre, aún cuando realidades nuevas en el ambiente mundial actual le confieren un carácter distintivo y obliga a nuevos y viejos actores a concertar acciones y a unir esfuerzos para lograr la superioridad competitiva.

Palabras clave: competitividad, competencia, mercado libre, ventaja competitiva, determinantes de la competitividad.

\begin{abstract}
Nowadays competitiveness is made up of "the new" paradigm that allows to prevail in the global World. Thus, it is inevitable to ask, was it required to be competitive to be successful in the international trade arena? Recognizing the discussion about it and its theoretical-conceptual density, the present paper studies this old notion whose meaning, in essence, is always the same one. This applies even though new realities in the present world-wide atmosphere confer to it a distinguishing character and new and old players are forced to organize actions and bring efforts together to obtain the competitive supremacy.
\end{abstract}

Key Words: competitiveness, competition, free market economy, competitive advantage, competitive determinants. 


\section{Marlene Peñaloza*}

\section{Competitividad: ¿nuevo paradigma económico?}

\section{Introducción}

\section{$\mathrm{E}$}

1 pasado reciente y los tiempos actuales están signados por grandes cambios en el ámbito competitivo, tecnológico, económico-social y político. Estos cambios se ven representados, en algunos casos, por el regreso de modelos viejos que la historia, en su constante devenir, les llena de nuevos contenidos. Entre éstos se encuentran la globalización y el libre mercado y, como contraparte, la competitividad, paradigma éste que desde hace algún tiempo se encuentra, cotidianamente, en la palestra pública y parece ser factor determinante para tener éxito en los entornos globalizados.

Precisamente, la noción de competitividad es de vieja data, pues subyace en las discusiones de los clásicos de la economía como Adam Smith y David Ricardo al abordar el tema de la competencia, constituyendo un concepto fundamental de la teoría económica. Se trata, entonces, de una noción vieja cuyo significado básico reside en lograr la superioridad entre pares, a partir de cualidades distintivas, para obtener un beneficio. Competir no es exclusivo de las personas, también compiten las organizaciones cuando se encuentran en un ambiente que las obliga a disputarse por obtener posiciones, aún

*Profesora Departamento de Empresas, Universidad de Mérida, Venezuela.

Recibido: 27 de febrero de 2003; Aceptado: 6 de noviembre de 2003 
sin tener las condiciones objetivas para ello. De manera que el término puede ser entendido como aptitud o capacidad para imponerse sobre otros, o bien como estado competitivo.

Sin embargo, ante el auge que ha tomado el término, especialmente en las últimas décadas, pareciera que se trata de un concepto surgido de las nuevas realidades. De ser así, es inevitable plantearse algunas interrogantes, como por ejemplo: ¿Acaso en el pasado no se requería ser competitivo para triunfar en los negocios?; ¿Cómo lograron la superioridad empresas y países de reconocido éxito en el ámbito comercial?; ¿Será que la lucha por sobresalir se sustenta en cualidades distintivas propias de cada contexto histórico?

Reconociendo la densidad del tema y la discusión en torno a éste, en la presente investigación documental se explora - sin mayores pretensiones- sobre esta vieja noción cuyo significado, según la tesis que se presenta, es el mismo de siempre. Las realidades nuevas en el plano: tecnológico, político y socio-económico han trastocado parte del andamiaje en que se sustentó por siglos la fortaleza competitiva de empresas y países. Esto ha generado otras fuentes de competitividad y un ambiente de tal complejidad que hace casi imposible participar sin nuevas competencias, sin reacomodos $y$ replanteamientos importantes sobre las formas de conquistar e imponerse en los mercados abiertos.

Con tal propósito se aborda - grosso modo- los cambios en el contexto de realidades mundiales nuevas, la conceptualización del término, el auge de la competitividad y el debate generado en torno a ésta. El análisis está centrado en las fuentes de competitividad y los eventos que caracterizan la competencia actual. Por último, se presentan las conclusiones derivadas de la investigación.

\section{Cambios en el panorama mundial}

El pasado reciente y los tiempos presentes están acompañados de cambios importantes en los planos: tecnológicos, políticos, socioeconómicos y competitivos. Si se remite especialmente al campo de la tecnología, los cambios han sido tan profundos que han suscitado la atención de los estudiosos, quienes le comparan y confieren tanta importancia como la que significó la invención de la máquina. Es 
innegable que la aparición de tecnologías nuevas como: la microelectrónica, la biotecnología y los materiales nuevos dan fe de ello. En éstas, la característica común es hacer que la actividad productiva sea intensiva en información y no en materia prima o mano de obra, que fue el elemento distintivo de la producción en masa.

Lo vertiginoso de estos cambios nos permite apreciar el surgimiento de un nuevo paradigma tecno-económico: el de la Tecnología de la Información y de las Comunicaciones (TIC) ${ }^{1}$, conformado por sectores importantes que evolucionaron rápidamente, como el de las telecomunicaciones y de los componentes electrónicos, entre otros. En el ámbito político, se sucedieron hechos impensables hace algunos años, dando un giro a la forma de concebir el panorama mundial. La caída del muro de Berlín, la desintegración del imperio soviético y, consecuentemente, la eliminación de la confrontación este-oeste, allanaron el camino para que el sistema capitalista se impusiera y con éste, el mercado como mecanismo regulador de las relaciones entre los agentes económicos distintos. Un nuevo ciclo comienza, teniendo de protagonista la economía liberal, y como signo la casi universalidad de las leyes económicas.

En el orden económico, el cambio en la manera de operar los mercados significó, dejar atrás concepciones viejas (el marxismo, el cepalismo) que en su momento guiaron al ser humano del siglo veinte. Hoy, en una especie de círculo, se tiene de vuelta al liberalismo, llamado modernamente, neoliberalismo (Huizzi, 1994). Con éste, la globalización entendida como interdependencia entre factores de producción en países diferentes. Asimismo, resurgen y cobran importancia el libre comercio ${ }^{2}$ y la competitividad como "nuevos credos" para acceder con éxito al ambiente imperante de competencia.

\section{Algunas definiciones sobre Competitividad}

Sin pretender ser exhaustivos, es preciso abordar algunos enfoques de la competitividad. Haciendo un ejercicio metodológico encontramos tres grupos de explicaciones en atención a los ámbitos en que se da el hecho competitivo: al interior de la empresa, a nivel del sector industrial y a nivel macro de la economía (Boza y Pérez 1996, p 41). 
En el ámbito de la empresa, la competitividad es vista como la capacidad para suministrar bienes y servicios igual o más eficientemente que la competencia, o en forma general, como señala Emeterio Gómez (1994) cuando afirma: "Sin mayores refinamientos conceptuales entenderemos por competitividad la capacidad de producir más a menor costo o con mayor calidad que los demás” (p. 12) ${ }^{3}$.

A nivel del sector industrial, la competitividad puede ser entendida como: "[...] la capacidad que tienen las empresas nacionales de un sector particular para alcanzar un éxito sostenido contra competidores foráneos, sin protección o subsidios" (Enright, Francés, Scott, 1994, p. 66).

En un ámbito mucho más amplio, coincidimos con el concepto de competitividad del Report of President's Comission of Industrial Competitiveness, en el que se sostiene que una nación o una empresa es competitiva si, bajo condiciones de libre mercado, es capaz de mantener o aumentar su participación en los mercados nacionales e internacionales, manteniendo o mejorando las rentas de sus ciudadanos o de su capital humano.

Si el lector es acucioso, identificará dos acepciones amplias en la manera de concebir la competitividad: como "aptitud o capacidad competitiva” y como "estado competitivo" (Guerrero, 1995). Es decir, como una cualidad subjetiva interna, que se deriva en superioridad frente a sus competidores y, como una realidad objetiva a partir de ciertas condiciones existentes en el entorno mediato e inmediato que la impulsan y la refuerzan.

\section{El nuevo auge de la competitividad}

Resulta interesante observar que, quizás, en ninguna otra época se dio tanta importancia a la competitividad como hoy día. Este paradigma que ha trascendido el mundo económico para aplicarse por igual a personas y empresas, desde hace algún tiempo se encuentra, cotidianamente, en la palestra pública y parece ser un factor determinante para tener éxito en el ambiente competitivo actual.

Ahora bien, dado su auge, resulta pertinente preguntarse si se trata de una palabra de moda o es como consecuencia de la dinámica de los tiempos nuevos. Bajo estos supuestos, es inevitable 
plantearse la interrogante de cómo hicieron en el pasado empresas y países de éxito reconocido en el ámbito comercial para lograr sobresalir entre sus pares. También surge la pregunta acerca de si la novedad está asociada a la presencia de determinantes nuevos de la competitividad y a las condiciones existentes en un contexto histórico específico.

Para dar respuesta a estas preguntas se inicia la temática, partiendo de la noción de competencia, la cual es tan vieja como el ser humano mismo. Desde que éste convivió en sociedad se vio obligado a adoptar conductas que le permitieran imponerse y sobresalir frente a otros hombres, los cuales le disputaban espacios y bienes. Así, los individuos compiten por naturaleza, la competencia constituye el "condimento de la vida"y se da en los campos principales de la naturaleza humana.

En este orden de ideas, la competencia puede ser considerada como: una actitud personal y, una forma de enfrentar al mundo propio de los seres humanos. No obstante, competir no es exclusivo de las personas, también compiten las empresas cuando al concurrir en un mercado intentan imponerse sobre otras, bien por alta concurrencia de empresas, aún sin poseer mayores cualidades distintivas, o bien a través de atributos diferenciadores. De este último caso se trata de capacidad competitiva.

En consecuencia, el término transciende el plano sociocultural, pasa al ámbito de la economía y constituye un concepto básico del instrumental analítico de la teoría económica. Su discusión subyace, inclusive en los planteamientos de los clásicos de la economía como Adam Smith, David Ricardo y Jonh S. Mill; o en pensadores como Joseph Schumpeter. Así, y sólo a título ilustrativo, se señala que Adam Smith (1723-90) -fundador de la ciencia económica- al cuestionar las ideas de los mercantilistas sobre el control de la economía, presentó algunos argumentos que hoy pudiesen enmarcarse dentro de lo que se entiende por competitividad. Sin embargo, es David Ricardo (1772-1823) el primer teórico en introducir la noción de la competitividad a través de su razonamiento sobre las ventajas comparativas, al considerar el comercio internacional siempre beneficioso para el país cuyos costos de producción del bien a intercambiar fuesen menores en términos relativos al del otro país con el cual se comercia. Bajo esta óptica, la competitividad se sustenta en la 
especialización y producción de los bienes en que se logre eficiencia relativa mayor (Spiegel, 1991).

No obstante, en la concepción clásica pareciera entenderse la competitividad como sinónimo de competencia, al concebirla como rivalidad entre sujetos económicos que buscan imponerse. De ser entendida así, puede ocurrir por alta concurrencia de empresas aún con escasos atributos diferenciadores. Sin embargo, de lo que se trata es de doblegar a los competidores con base a las ventajas competitivas. De aquí que la competitividad debe abordarse más allá de la competencia, pues no sólo se trata de imponerse, sino de hacerlo con cualidades superiores. Esta superioridad competitiva estará en función de las peculiaridades de cada industria en particular, de la estructura del mercado y de las condiciones generales del entorno en que se desenvuelven las empresas.

Más aún, la óptica bajo la cual se ve a los competidores como a simples contrincantes puede resultar limitada y antieconómica, pues se puede ser rival en un área y socio en otra, dadas las nuevas realidades que enfrentan las empresas debido, por ejemplo, a los costos fijos altos en I\&D que obliga a la creación de alianzas estratégicas.

Joseph Schumpeter (1883-1950) también se refiere a la guerra constante entre empresas y pone de manifiesto que la competencia entre las mismas ocurre en una carrera por incorporar productos y procesos nuevos. Introduce, en su planteamiento, la noción de las revoluciones tecnológicas de largo aliento y el concepto de destrucción creativa, que es el proceso incesante de sustitución de métodos y bienes por otros nuevos liderados por las empresas grandes.

Por la década de los sesenta, el tema de la competitividad se impuso en Europa a consecuencia de la pérdida de mercados frente a las empresas norteamericanas, trasladándose en los años siguientes a los Estados Unidos. Es a partir de 1973 cuando el tema aparece en los diarios, revistas y en la literatura norteamericana, ante el desplazamiento de las preferencias de los consumidores estadounidenses hacia productos de procedencia asiática. Una razón fue la competitividad baja de este país cuya productividad laboral, en la mayoría de las ramas de la industria manufacturera al terminar la segunda guerra mundial, fue dos o tres veces superior a las industrias equivalentes en Europa y, más aún respecto de los países de Asia. 
En este contexto, surgen los trabajos de Michael Porter, académico reputado de la Escuela de Negocios de la Universidad de Harvard, quien coloca en la palestra mundial el interés por el tema, sobre todo a partir de la publicación de su libro La ventaja competitiva de las naciones. En esta obra el autor traslada el concepto de ventaja competitiva, que hasta entonces se empleaba sólo a las empresas y lo aplica a los países, sosteniendo que éstos pueden construir sus propias ventajas competitivas. En este sentido, Porter (1991) afirma:

La competitividad ha pasado a ser una de las preocupaciones cardinales del gobierno y de la industria de todas y cada una de las naciones. La cuestión es cómo brinda una nación un entorno en el que las empresas sean capaces de mejorar e innovar más aprisa que sus rivales extranjeras (p. 47).

Al estudiar las condiciones prevalecientes en diez países exitosos en el comercio internacional, Porter identifica cuatro áreas grandes que representan los determinantes de la competitividad, a saber: a) condiciones de los factores, b) condiciones de la demanda, c) las industrias relacionadas y de apoyo, y d) la estrategia, la estructura y la rivalidad de las empresas del país.

Los estudios de Porter crean revuelo, tanto en el mundo de los negocios como en el académico. En primer lugar, porque objeta el argumento de Ricardo, al establecer que las ventajas comparativas estáticas no son el factor determinante para el crecimiento económico. Un país puede crear sus propias ventajas mediante el desarrollo de la tecnología, infraestructura y práctica gerencial, entre otras. En segundo lugar, el hecho mismo de extrapolar a los países un concepto que tradicionalmente se consideraba propio de las empresas resulta per-se novedoso, de modo que sus investigaciones y propuestas teóricas se convirtieron en lectura obligatoria, tanto en medios académicos como empresariales.

\section{El debate sobre la competitividad}

Otro académico, Paúl Krugman se une a la discusión con un artículo polémico titulado: "Competitiveness: A dangerous obsession" (Krugman, 1994) en el que crítica no sólo a colegas, sino directa- 
mente los planteamientos de Michael Porter. En ese sentido, muestra su desacuerdo sobre la vinculación de la riqueza de un país con el éxito en los mercados mundiales y con el papel asignado a la competitividad como meta obligatoria para que una nación acceda a mejores niveles de bienestar.

Según Krugman, no hay similitud entre la competencia que realiza una empresa y la que realiza un país, el comercio internacional no es un "juego de suma cero" donde el desarrollo se logra en detrimento de los demás. De otro lado, sostiene que el incremento del nivel de vida de un país es, en promedio, igual al de su productividad interna y no depende de la competitividad respecto de sus competidores. Agrega, además, que no pueden extrapolarse los términos como lo hace Porter al referirse a la ventaja competitiva para las naciones, por cuanto una compañía puede ser eliminada del mercado o declarada en quiebra, lo que no ocurre en el caso de un país, pues no existe un "bottom line" como en el caso de las empresas.

Aún cuando se pudiese estar de acuerdo con parte de los planteamientos de Krugman, lo cierto es que los conceptos emitidos causaron desconcierto a los amigos del comercio libre. Pareciera además una confrontación entre los que defienden o adversan la apertura de los mercados, o mejor, una reedición de la vetusta discusión entre liberalismo y proteccionismo.

Al revisar antecedentes es fácil apreciar que no es un concepto creado por las realidades mundiales nuevas, más bien es un término básico de la teoría económica acuñado en las esferas académicas, con cierta rigurosidad científica, pero con una impregnación ideológica notable. Es precisamente, la expresión de la ideología lo que caracteriza a las economías basadas en las leyes del mercado, por lo cual al imponerse, casi en forma universal, el sistema capitalista se constituye en un concepto instrumental del discurso económico-político dominante. En este contexto, se comprenden las causas que le han traído de vuelta con tanta fuerza.

Aclarado el primero de los interrogantes y en el interés de sustentar el planteamiento central de esta investigación, de si en el pasado no se requería ser competitivo para triunfar en los negocios, y cómo empresas y países de éxito reconocido en el ámbito comercial lograron superioridad competitiva, es pertinente conocer las fuentes que 
tanto ayer como hoy son factores claves de la competitividad de una persona, empresa y país. En este orden de ideas, a continuación se describen las más importantes. Algunas de éstas las hemos denominado tradicionales. Luego se describen otras vinculadas al entorno nacional e internacional y finalmente los determinantes nuevos.

\section{Fuentes de la competitividad}

\section{Tradicionales:}

- División del trabajo y especialización: Estos dos elementos son básicos para proporcionar -trátese de individuos, organizaciones o países- un bien o servicio igual o mejor que los existentes en el mercado, siendo importante hacerlo en lo que se esté mejor dotado, bien por la naturaleza o por el propio esfuerzo (Gómez, 1994). Así, países como Venezuela, Nueva Zelanda, Canadá y Australia se especializaron en la producción y exportación de minerales y recursos naturales.

- Calidad: Producir con calidad implica cuidar que los productos cumplan su función técnica y que lleguen en la forma y las condiciones que exige el comprador. Esto implica superioridad en los procesos tecnológicos, en la gestión administrativa y en los intangibles que intervienen para el disfrute de quien compra. Asimismo, requiere innovación, flexibilidad de la organización, adaptación rápida a los cambios en los gustos de los consumidores, tiempos de entrega cortos, canales de distribución eficientes, procesos y servicios de acuerdo a los requerimientos de los clientes. Países como Japón son propiciadores del modelo de calidad total como instrumento para alcanzar la calidad.

- Capacidad gerencial, financiera y cultura organizacional: Según la economía evolutiva, las empresas tienen unas "rutinas organizativas", las que junto con los recursos físicos y humanos y la tecnología, constituyen la base de la ventaja competitiva interna (Valdaliso y López, 2000). El uso óptimo de dichos factores conduce a la productividad, elemento consustancial con la competitividad. 
- Productividad: La productividad es sinónimo de rendimiento. En términos sencillos, se entiende como: la utilización eficiente de los factores productivos al proporcionar bienes y servicios. Así, la empresa al hacer uso óptimo de los recursos (insumos) puede lograr una ventaja competitiva interna. Dicha ventaja está ligada a la existencia del efecto experiencia y a las economías de escala y viene dada en términos de costos menores en la fabricación y gestión del producto, calidad de los mismos e imagen, entre otros. Ello implica para la empresa: dominio tecnológico, mejora continua de los procesos productivos, y la preparación y capacitación del recurso humano.

Los niveles altos de productividad de naciones abanderadas del comercio internacional como Estados Unidos de Norteamérica, Alemania y Japón son reconocidos. El comportamiento del Producto Interno Bruto (PIB) por empleado en estos países a partir de 1960 y por un período de treinta años -en el caso de los Estados Unidoscreció de 100 a casi 155, mientras en Alemania ha llegado hasta más de 240 y en Japón está por encima de 460 (Batra, 1994, p. 89). Es decir, productividad y competitividad van juntas, aún cuando en opinión de Avalos (1994) “[...] en algún momento se puede ser competitivo sin que la productividad sea muy alta, y se pueden tener tasas muy altas de productividad sin ser competitivo" (p. 26). El primer caso puede ocurrir cuando por costos bajos en alguno de los factores de producción bienes de poca calidad son competitivos por ofrecerse a precios menores en comparación con sus competidores. Como ejemplo, pueden citarse los candados y los mahones, provenientes de China y comercializados en Venezuela en condiciones de "dumping". El segundo caso podría darse cuando productos con la calidad requerida llegan en mal estado por causa del manejo y de una infraestructura deficiente. Lamentablemente, un ejemplo de ello se observa en los puertos venezolanos que por lo engorroso e ineficiente de sus procedimientos limita la competitividad en mercados foráneos de frutas apetecibles como el mango, la piña y la patilla. 
- Tecnología: Factor clave para cualquier nación o empresa con deseos de superioridad en el mercado en el cual compite, constituye una herramienta fundamental para la creación de ventajas competitivas dinámicas. También es reconocido que el incremento de la productividad y de los ingresos depende, en gran medida, "[...] de un proceso continuo de cambio técnico, que incluye la introducción de productos nuevos y mejorados y maneras nuevas de organizar la producción, la distribución y comercialización" (Freeman, 1993, p. 89).

Los países altamente competitivos son aquéllos con gastos elevados en las siguientes áreas: investigación y desarrollo, ciencia básica y aplicada, inversión en equipos y formación del recurso humano. Consecuentemente ello conduce a la invención, la innovación y, por consiguiente, a disponer de tecnología de punta. La pérdida de mercados que ha afectado en los últimos años las industrias manufacturera y automovilística del Reino Unido, entre otros países, se ha asociado, justamente, a la declinación relativa en estas actividades.

En resumen, estas fuentes pueden agruparse en dos grandes categorías, según la ventaja competitiva que proporcione:

- Eficacia Operativa interna: relacionada con la especialización, la productividad, la capacidad tecnológica y los recursos y las capacidades de la empresa.

- Poder de mercado: relacionada con algunas de las anteriores, también con la calidad y otras cualidades distintivas como la marca, empaque, diseños y/o servicios.

Cualquiera de estas categorías, sola o en conjunto puede distinguir una organización y constituir la ventaja distintiva, así ha ocurrido antes y así ocurre ahora.

\section{Vinculadas al entorno nacional}

Hoy día hay otro factor del que no se tiene mayor control, que constituye un aspecto clave para la competitividad, nos referimos al entorno, por lo que a la aptitud o capacidad para imponerse deben 
también considerarse las condiciones macroeconómicas y microeconómicas en las que se desenvuelve la actividad comercial. En el caso concreto de las empresas debe considerarse, además, la estructura del sector industrial en la cual se compite, la relación de fuerzas existentes en el sector y las posiciones ocupadas por los competidores en el mercado de referencia (Lambin, 1995).

- Factores macroeconómicos: Entre estos factores se encuentra la tasa de inflación, tasa de cambio, tasa de interés y el equilibrio fiscal. Del mismo modo, existen otros factores como lo son: las políticas públicas, el sistema impositivo y legal, la eficiencia de los servicios públicos, la infraestructura, el sistema educativo y la fortaleza institucional. Adicionalmente y con un rol preponderante, la actuación de los gobiernos desempeña un papel fundamental pues es su responsabilidad procurar la estabilidad macroeconómica, orientar el gasto público, regular el sistema financiero y, en fin, crear un entorno favorable a la competitividad nacional. Los países que han desarrollado políticas eficientes en estas áreas, generalmente exhiben niveles altos de competitividad.

- Factores microeconómicos: En el plano de la microeconomía, la conducta de las empresas y de los individuos frente al hecho competitivo desempeña un papel determinante. La disposición de las empresas a mejorar constantemente, a buscar continuamente nuevas tecnologías que les permitan ofrecer productos con la calidad que el mercado demanda, a contribuir en la formación de su mano de obra, a incrementar su productividad, a innovar y a posicionarse por la calidad de sus productos u otras características distintivas -no por la protección gubernamental- conforman vías para sobresalir entre sus pares.

Los individuos por su parte representan, por sí, una fuente para la superioridad competitiva al extremar sus capacidades para alcanzar mayor eficiencia en los procesos de fabricación, diseño y comercialización de los productos. Al constituirse en demanda exigente de tales productos, obligan la colocación en el ámbito nacional de bienes y servicios con calidad de exportación. 
- Factores relacionados con el sector industrial: Según Porter (1981) el sector industrial "[...] tiene una fuerte influencia al determinar las reglas del juego competitivo, así como las posibilidades estratégicas potencialmente disponibles para la empresa" (p. 25). Es decir, la capacidad de una organización para explotar la ventaja diferenciadora en su mercado la determina tanto la estructura del mercado (número de competidores), como la posición competitiva que ostente (en atención a la estrategia básica adoptada) y las fuerzas rivales. Según el mismo autor, están constituidas por los competidores directos, los potenciales, los productos sustitutos, los clientes y los proveedores. Dentro de este mismo contexto, la teoría de los recursos y las capacidades también reconoce la importancia que tiene el sector industrial al centrar su análisis en las competencias internas que en combinación con el sector industrial determina la ventaja competitiva.

Hasta aquí se puede afirmar que tanto en el pasado como en el presente la competitividad de países y empresas se ha sustentado en algunas de estas competencias. Sin embargo, en épocas anteriores factores como el entorno y los referidos a la microeconomía no ocuparon un lugar relevante como el que tienen por estos días.

No obstante, debido a los cambios ocurridos en el ámbito mundial han surgido determinantes nuevos que revolucionan los modos y las maneras para imponerse en mercados abiertos, desplazando al que constituyó, por largos años, la competitividad de las empresas y naciones, nos referimos a las ventajas comparativas. Este "break-out" constituye un hecho de suma importancia pues los activos tangibles dan paso a los intangibles y a una riqueza que no radica en las materias primas que se posean, en el tiempo y en el espacio geográfico, sino en una riqueza que, aún cuando simbólica, es real y palpable. Según Chiavenatto (2002). "Es la sustitución de la economía basada en la manufactura y la explotación de los recursos naturales a una economía basada en el valor del conocimiento, en la información y en la innovación” (p. 34). 


\section{Nuevas fuentes de competitividad}

- Dominio del Conocimiento: A partir de los años ochenta, diferentes fuerzas irrumpen y generan una serie de eventos como, los avances tecnológicos y la desregulación de las telecomunicaciones y de los transportes, que han permitido la circulación libre de las ideas, tecnologías, bienes físicos, servicios y flujos financieros. Atrás quedó la producción industrial basada en las chimeneas, los mercados desconectados y las economías semiaisladas; los factores de producción se entrelazaron. Estos eventos condujeron a determinantes nuevos para la competitividad, entre los que se destaca el dominio del conocimiento, el cual constituye, por excelencia, la gran riqueza inmaterial de cualquier persona, organización o país. Es la época del conocimiento, del capital humano y del capital intelectual.

Es de reconocer que el dominio cognitivo siempre representó la clave para el avance tecnológico y, éste a su vez ha sido el soporte para el desarrollo y predominio de unas naciones sobre otras. La diferencia en esta época estriba en el grado de abstracción que ha alcanzado, requiriéndose hasta para las actividades más sencillas desarrolladas por el ser humano.

Hoy como nunca antes, las competencias están basadas en el "know-how", convirtiéndose, no solamente en el recurso clave para lograr ventajas competitivas, sino que en sí mismo constituye una ventaja competitiva. "De poco valen los edificios y las máquinas para evaluar o invertir en una empresa, lo importante son los contactos y el poder del equipo de mercadeo, las ventas, la capacidad de sus ejecutivos para organizar y dirigir, y las ideas que bullen en la cabeza de sus empleados" (Toffler, 1996, p. 88).

En la actualidad, las llamadas tecnologías blandas son las que sustentan la competitividad de empresas y países. En Venezuela, negocios pequeños dedicados a la consultoría, a la orfebrería y a la artesanía en general, se han apoyado en la inventiva, la creatividad y las destrezas para conquistar y posicionarse en nichos de mercado, tanto dentro como fuera del país. Éstas harán posible que cada nación y cada empresa construyan sus propias ventajas competitivas ${ }^{4}$. 
Cuenta poco que una nación posea recursos naturales inmensos cuenta poco, si no se dispone del conocimiento para aprovecharlos. Un ejemplo palpable es la existencia, en nuestro país, de las reservas mayores, en el ámbito mundial, de petróleo pesado y extra pesado, cuya utilidad es casi nula si no se dispone de alta tecnología y el "know-how" para transformarlo en un producto comercializable.

- Poder de la Información: En la llamada sociedad del conocimiento, la posición competitiva de los países, las industrias, las instituciones y las personas está sustentada en la tecnología, la investigación, el conocimiento y la información.

Ésta constituye hoy, más que nunca, una fuente que facilita u obstaculiza la participación con éxito en el mundo sin fronteras. Es de reconocer que la información, igual que el conocimiento, siempre ha desempeñado un papel vital en el desarrollo económico y en la capacidad para sobresalir entre pares, trátese de personas, compañías o naciones. Sin embargo, el avance logrado en la microelectrónica y la automatización ha cambiado la vida de empresas y países, hasta el punto de considerar que se ha producido un proceso de ruptura no visto desde la revolución industrial, que ha originado formas nuevas de organización que se han derivado en ventajas competitivas.

Hoy, las computadoras, los lectores ópticos, los dispositivos de rayos láser, la Internet y la robotización, transforman los sistemas de producción, distribución y comunicación. Las redes electrónicas, la comunicación satelital y muchas otras nuevas tecnologías como las llamadas "redes inteligentes" facilitan la transmisión, recepción y evaluación de los datos necesarios e imprescindibles para operar en la era de la informática y de los mercados globalizados (Friedman, 2000). Las empresas y los países se disputan por estar interconectados, pues ello garantiza conocimiento de mercados, clientes, proveedores, fuentes de financiamiento, productos disponibles, movimientos de los competidores y un sinfín de otros aspectos sin los cuales no es posible tomar decisiones acertadas. No en balde se le considera un arma estratégica sin la cual la competitividad se vería seriamente afectada. Por lo tanto, "[...] aquellas organizaciones capaces de recolectar la información y transformarla con rapidez en una oportuni- 
dad para un nuevo producto o servicio, antes que otras lo hagan, son las más exitosas", (Chiavenatto, 2002, p.33).

- Otros Activos: En este contexto, a medida que el capital intelectual toma cada vez mayor peso competitivo, otros activos tales como los clientes, la fuerza laboral y los inversionistas se constituyen en factores de competitividad empresarial y nacional.

Los clientes representan un factor básico en la pelea competitiva, pues ante la variedad de bienes y servicios cada vez le resulta más difícil a las empresas proveer un valor superior y lograr su fidelidad. En el pasado se daba por descontada la satisfacción de sus necesidades, hoy por el contrario la lucha es a muerte por conservarlos; a su vez, los clientes se han constituido en una fuente de información valiosísima disputada por los comerciantes, seguros y la banca, entre otros. La fuerza laboral, por su parte, constituye el talento humano, pilar central en la construcción de una ventaja competitiva real. Los inversionistas, representan el músculo financiero.

- Preservación del medio ambiente: Otra fuente nueva de competitividad a destacar desde mediados de la década del setenta, es la relacionada con la preservación del medio ambiente y la inocuidad de los productos, debido al deterioro, escasez, la depredación e incluso, la desaparición de recursos medioambientales importantes e indispensables para la calidad de vida presente y futura.

Frente a esta situación y para procurar ganarse la aceptación de los clientes, las empresas toman precauciones en sus procesos productivos y en la elaboración de sus productos para proteger el ecosistema. Los gobiernos, por su parte, se proveen de mecanismos para lograr un desarrollo con sentido humano. Sobre este respecto, De Bono (1993) apunta: "Hay importantes capitales de riesgo que sólo invierten en empresas con condiciones ambientales seguras. Hay fabricantes que esperan aumentar la participación de mercado marcando sus productos como amigos del medio ambiente" (p. 53).

Una vez reconocidas estas nuevas fuentes y sus implicaciones para 58 
el hecho competitivo actual, es importante establecer un paralelismo entre la manera de concebir y practicar la competitividad en el pasado en comparación con el presente, a fin de puntualizar los cambios ocurridos en el tema objeto de estudio.

En tal sentido, hoy como ayer, los participantes en el comercio intra e internacional tienen que gozar de cualidades distintivas para alcanzar el éxito. Del mismo modo, tanto en el pasado como en el presente, la productividad (determinante de la riqueza) y la tecnología (determinante de la calidad de los bienes y servicios) constituyen los pilares fundamentales para apalancar la superioridad entre competidores. También lo constituyen la especialización, la división del trabajo, los recursos y las capacidades de la empresa, así como en mayor o menor grado, los demás factores señalados.

No obstante, en la economía global moderna el juego competitivo cambia y el éxito viene dado no sólo por poseer capacidad o aptitud competitiva, o por la cantidad de árboles, petróleo o mano de obra que tenga una nación, sino por disponer de "know-how", de información, de un entorno favorable, de clientes satisfechos, del respeto al medio ambiente, junto a la actuación sincronizada entre gobierno-empresas e individuos. Aquí estriban las diferencias. Aún cuando a primera vista parece simplista, por cuanto estos factores de alguna forma siempre han estado presentes en la competitividad de las empresas y los países, nunca habían desempeñado el papel que tienen hoy, nunca como ahora los factores de producción habían tenido tal entrelazamiento, el conocimiento y los clientes jugaron un rol tan clave, la cibernética ocupó lugar semejante y las preocupaciones por un desarrollo sustentable recibieron gran consideración.

En consecuencia, éstos y otros eventos han trastocado buena parte del andamiaje que por siglos sustentó la competitividad de las empresas y naciones, surgiendo determinantes nuevos y un ambiente de tal complejidad que a la par de hacer casi imposible participar sin esas competencias nuevas, exige reacomodos importantes y replanteamientos en las formas de conquistar e imponerse en mercados abiertos. De allí la tendencia a constituir alianzas estratégicas (fusiones, adquisiciones, "joint-venture") y a conformar bloques económicos como: la Comunidad Andina, la Comunidad Económica Eu- 
ropea, el Tratado de Libre Comercio, el Mercado Común del Sur, por nombrar los más conocidos. En cuanto a la forma de relacionarse y lograr la fidelidad de los clientes, maneras nuevas de distribución y comunicación con los consumidores tales como el mercadeo directo, la Internet, el mercadeo relacional, entre otros, cobran una importancia capital y obligan a replantear los modos de mercadear los bienes y los servicios.

Finalmente, la interdependencia tiene la particularidad de facilitar la construcción de ventajas competitivas. Éstas últimas se crean a partir de las oportunidades que ofrecen los mercados abiertos, sustentados en una asignación eficiente de los recursos productivos y en la inventiva, la creatividad y el "know-how" de la propia nación o de la empresa en particular.

De manera que se incorporan unos elementos definitorios para triunfar en los mercados actuales, logrando imponerse y sobresalir aquéllos que dominen estas fuentes nuevas, lo que ahondará la brecha profunda y las asimetrías entre países y empresas que puedan (o no) acceder a elementos nuevos de dominación mundial. Es el sello que imprimen las nuevas realidades.

Llegado a este punto y para finalizar, en este artículo se intentará mostrar la relación entre las condiciones económico-sociales de determinado contexto histórico y la preeminencia de algunas fuentes, con el objetivo de descubrir las causas que llevaron a que unos determinantes se impusieran sobre otros.

\section{Fuentes vs. contexto histórico}

Desde la invención de la máquina de vapor y, prácticamente hasta mediados de siglo XX, la preocupación de las empresas estuvo orientada a la optimización de los recursos productivos tanto materiales como financieros, a fin de reducir los costos e incrementar su producción. Las competencias empresariales se basaron en la capacidad para reducir costos, lo que les llevó a ser líderes en esta área. Los clientes se mostraban dispuestos a absorber todo (o casi todo) lo que se producía, pues su interés estaba centrado en obtener el producto, sin dar demasiada importancia a las cualidades del mismo. Destacan en

este sentido la línea de montaje de Henry Ford con productos 
estandarizados como su famoso Modelo T, y los esfuerzos realizados por empresas como General Motors y Chrysler para obtener ventajas competitivas basadas en la reducción de costos. Tal comportamiento empresarial permite argumentar que en este período la productividad constituyó (y continúa siendo) la principal fuente de competitividad.

A la par de la dimensión productividad y por una demanda creciente por parte de los países del primer mundo necesitados de materia prima, otras naciones con recursos naturales importantes o mano de obra abundante, optaron (por interpuestos más que por cuenta propia) por atender los requerimientos de los países industrializados apalancando su competitividad en las ventajas comparativas estáticas. Así, por ejemplo, los países latinoamericanos se hicieron competitivos en industrias pertenecientes al sector primario de la economía con lo cual, aún hoy día, continúan abasteciendo mercados externos. Por su parte, las naciones asiáticas lograron que empresas transnacionales importantes se instalaran en sus territorios, atraídas por mano de obra barata o abundante.

A partir de los años cincuenta y hasta nuestros días, la existencia de una demanda en constante crecimiento, la saturación de algunas necesidades, el mejoramiento de los procesos productivos, las nuevas tecnologías y la internacionalización creciente de los mercados ha obligado a las empresas a afianzarse en otras competencias como la calidad, la imagen, las marcas, los envases, los diseños y las formas nuevas de distribución y promoción. Ello se constituyó en una ventaja competitiva externa expresada en el poder de mercado y denominada estrategia de diferenciación. Hoy por hoy, productos cuya función técnica es igual o muy similar, se distinguen por su calidad, su nombre de marca, su empaque, la rapidez en su entrega u otros atributos como los tamaños, los colores y los usos. Las competencias de estas empresas están fundamentadas en el valor que ofrecen al mercado.

Un dato más reciente es la problemática ambiental, la cual no tuvo mayor significación en los procesos de industrialización de los países desarrollados, pues eran otras las preocupaciones prevalecientes en las naciones dominantes. El culto por la productividad no llevó a reconocer los efectos secundarios inmanentes a tal desarrollo. Sin 
embargo, ante la radioactividad artificial, las emisiones industriales, la contaminación agrícola y, en general, el deterioro en la calidad de vida de la mayoría de los seres humanos cobró fuerza una temática más amplia como es el desarrollo sustentable.

Actualmente la llamada "coeficiencia," 5 se está considerando a la hora de seleccionar unos bienes por otros. No están muy lejanas las dificultades confrontadas por Petróleos de Venezuela (PDVSA) al introducir la gasolina al mercado de la Florida (USA), pues se le acusaba de contaminante.

Finalmente, la aparición de la sociedad del conocimiento está asociada con el traspaso de poder de los factores tradicionales de la producción -tierra, trabajo y capital- a una fuente hecha de símbolos. Esto, por supuesto, significa una revolución en comparación con la base económica que sustentó por siglos el desarrollo económico de las naciones. Según Toffler (1996), se está frente al cambio de poder más profundo en la historia de la humanidad, aún cuando, a decir verdad, todos los sistemas económicos se asientan sobre una base de conocimiento, que nunca ocupó un lugar tan importante.

El avance del conocimiento y de las tecnologías de la información, desde nuestra óptica, es una respuesta más del propio sistema capitalista frente a la crisis estructural que desde los años sesenta se venía sufriendo y que afloró con otra crisis: la crisis petrolera de 1973. El encarecimiento de las materias primas, la productividad baja de las empresas, los efectos depresivos sobre la inversión, el empleo y el consumo (Valdaliso y López, 2000, p. 460), entre muchos otros problemas, se encararon liberalizando sectores tan importantes como las telecomunicaciones, reduciendo las barreras al comercio libre y dedicando recursos ingentes en investigación de nuevas tecnologías, entre otras decisiones.

También el predominio del conocimiento y de la informática, lo asociamos con el ascenso de una fuerza laboral nueva cualitativa y cuantitativamente diferente a otras épocas. Esta clase de trabajador, que sustituyó al trabajador industrial, es el nuevo grupo dominante denominado por Druker (1996) como el "trabajador de conocimientos”. Según el mismo autor, este trabajador se caracteriza por poseer una educación bastante formal y por su capacidad de adquirir y aplicar conocimientos teóricos y analíticos, formación que 
con el tiempo le ha permitido avanzar progresivamente en el desarrollo científico y tecnológico, inventando e innovando, dado que la aplicación y la especialización constituyen su razón de ser. La investigación de mercado, el diseño de productos y una campaña publicitaria requieren de conocimientos avanzados aplicados a una realidad concreta. De aquí que el mercadeo haya devenido en una variable decisiva en el comercio internacional como también las tecnologías nuevas como la microelectrónica y la biotecnología.

A su vez, el avance de la cibernética trajo consigo la desregulación de las telecomunicaciones lo que convirtió al mundo, metafóricamente, en una aldea, con el consiguiente impacto económico-social, modificando, entre otros, el comportamiento de compra de los consumidores. Hoy día los consumidores están mucho mejor informados y tiene mayor conocimiento sobre los productos a adquirir y los derechos que les asisten como actores principales en una economía dominada no ya por los gobiernos ni por las empresas, sino por su poder de compra, más aún, por ser en si mismos generadores de una información, por la que se disputan las empresas.

\section{Conclusiones}

La noción de competitividad es un concepto viejo que puede ya entreverse en las discusiones de los economistas clásicos al tratar el tema de la competencia. Sin embargo, va más allá de ésta, en tanto y en cuanto, la lucha por imponerse viene dada por la superioridad de los atributos.

El ámbito en el cual se sitúa el tema competitivo, trasciende el personal y el de la empresa para abarcar al país, estableciendo una interacción fuerte entre la organización y su entorno, con influencia marcada de este último, por lo cual las variables microeconómicas influyen y son influenciadas por variables macroeconómicas con significación importante de ambas. De aquí que, fuentes nuevas se sume a los determinantes tradicionales y hagan diferente la lucha competitiva actual en contraste con tiempos pasados.

Frente a estas nuevas realidades, la competitividad empresarial y nacional es el resultado de la existencia de un conjunto de condiciones prevalecientes a lo largo de la historia económica. Está determi- 
nada por el modelo económico dominante, las capacidades de la empresa, la estructura de los mercados y la influencia del entorno. La misma deviene de una combinación de factores y no de un factor único, por lo que se puede afirmar que no existe una estrategia competitiva universal para tener éxito en los mercados, más bien depende de las características distintivas que ostente la organización o el país, en comunión con la realidad circundante, con el papel clave de la tecnología y la productividad.

No obstante y como paradoja, la propia dinámica de los mercados actuales hace mucho más difícil el mantenimiento de la superioridad competitiva, siendo imprescindible la actuación sincronizada del gobierno, empresas e individuos, a fin de crear el clima necesario que permita mantener tal superioridad. De los esfuerzos compartidos, se generará: el ambiente propicio, las destrezas necesarias; los productos con los atributos que el mercado demanda y las condiciones adecuadas para competir con éxito, local y globalmente. 
COMPETITIVIDAD: ¿NUUEVO PARADIGMA ECONÓMICO?

\begin{abstract}
Notas
${ }^{1}$ Denominado así por Carlota Pérez según lo citado por Freeman (1993).

${ }^{2}$ Ianni, O., señala que el comercio fuera de las fronteras siempre existió, sin embargo, tal vez en ninguna época del desarrollo de la civilización, la interdependencia entre los factores de producción en el ámbito mundial fue tan marcada como a partir de la década de los ochenta.

${ }^{3}$ Indudablemente, será más fácil de medir en empresas que producen bienes físicos.

${ }^{4}$ Todo ello tiene connotaciones importantes para el concepto de productividad pues éste va mucho más allá de la eficiencia al estar relacionado con la calidad, la imagen y la comercialización de los productos.

${ }^{5}$ Acción de producir bienes y servicios útiles al tiempo que se reduce el uso de materias primas y la producción de contaminantes.
\end{abstract}


Marlene Peñaloza

\section{Bibliografía}

Avalos, Ignacio (1994), Empresa, tecnología y competitividad". Revista Talento. Premio estímulo al conocimiento. № 1, abril. Caracas.

Batra, Ravi (1994), El mito del libre Comercio. Argentina. Editorial Vergara.

Bosa, María y Pérez, R. (compiladores, 1996), Seguridad jurídica y competitividad. Caracas, Ediciones IESA.

Chiavenatto, Adalberto (2002), Gestión del Talento Humano en un ambiente dinámico y Competitivo. México, McGraw Hil.

De Bono, Edward (1993), Más allá de la competencia. La creación de nuevos valores y objetivos de la empresa. España, Paidós.

Enright, Michael, Francés A., y Scott E. (1994), Venezuela: El reto de la competitividad. Venezuela, IESA.

Drucker, Peter (1996), La administración. La organización basada en la información. La economía. La sociedad. Colombia, Grupo Editorial Norma.

Guerrero, Diego (1995), Competitividad: teoría y política. España, Ariel Economía.

Gómez, Emeterio (1994), La competitividad. Revista Talento. Premio estímulo al conocimiento, № 1, Abril. Caracas.

Huizzi, Raúl (1994), Liberalismo, Neoliberalismo y Teoría Económica. Mérida, ULA-FACES.

Freeman, Christopher (1993), El reto de la innovación: la experiencia de Japón. Caracas, Editorial Galac.

Friedman, Thomas (2000), "The Lexus and the Olive Tree". New York, Anchor Book.

Ianni, Octavio (1996), Teorías de la globalización. Madrid. Siglo XXI Editores.

Krugman, Paúl (1994), Competitiveness: a dangerous obsession. Journal Foreing Affairs, Volumen 3. New York, Free Press.

Porter, Michael (1991), La ventaja competitiva de las naciones. Argentina, Editorial Vergara. 
COMPETITIVIDAD: ¿NUUEVO PARADIGMA ECONÓMICO?

Porter, Michael (1981), La ventaja competitiva. Argentina, Editorial Vergara.

Spiegel, Henry (1991), El desarrollo del pensamiento económico. Barcelona Ediciones, Omega.

Toffler, Alvin (1996), El cambio del poder. España. P\&J Editores.

Valdaliso, Jesús y López, S., (2000), Historia económica de la empresa. Barcelona. Editorial Crítica.

World Economic Forum (1993), The world competitiveness report. IMD, Lausanne. 
